\title{
Fala, escrita e gramática
}

\section{Maria Beatriz Nascimento Decat Universidade Federal de Minas Gerais}

\section{Abstract}

The present work attempts to bring together spoken language, written language, and grammar teaching in the context of language teaching, in particular the teaching of Brazilian Portuguese. Among the topics discussed, emphasis is placed on the need to take spoken language into account when it comes to language teaching. I propose that one should take the dynamics of speech as the starting point in the examination of the processes that are responsible for the organization of languages. These processes result from the communicative-interactional activities in which language users are normally engaged. 


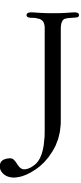

á se tornou usual, no meio acadêmico de modo geral, a discussão sobre os objetivos e a necessidade, ou não, do ensino da gramática na escola. Em meio às diversas tendências no tratamento do assunto, os que defendem o ensino da gramática se vêem às voltas com, pelo menos, uma questão polêmica, qual seja a de que gramática ensinar. Envolvidos com noções como oralidade e escrita, presentes nos estudos e discussões mais recentes sobre a linguagem, os profissionais do magistério vêem crescerem sua preocupação e suas angústias diante de orientações como as estabelecidas nos Parâmetros Curriculares para o Ensino da Língua Portuguesa no sentido de se promover a incorporação da língua falada ao ensino. Acostumados a lidar somente com a língua escrita, parecem estar diante de um impasse. E novamente surge a questão: que gramática ensinar? Ou, ainda: como conciliar fala, escrita e ensino de gramática? E mais: como ensinar a gramática da língua e, ao mesmo tempo, trabalhar com a língua falada?

Pretendo apresentar, aqui, algumas reflexões sobre esse tema que tanto preocupa os que lidam com o estudo e, principalmente, com o ensino da língua portuguesa. Para tanto, a exposição se estrutura em três partes, além dessas considerações iniciais e da conclusão. Numa primeira parte, serão discutidos alguns aspectos e noções sobre gramática a partir de um texto retirado do prospecto de divulgação do lançamento da Gramática de usos do Português (NEVES, 2000), cujo teor é desenvolvido pela autora na apresentação dessa obra. A segunda parte da exposição consistirá de algumas considerações sobre a língua falada e suas relações com a língua escrita, sempre tendo como preocupação a questão do ensino da gramática. Na terceira parte, serão apresentadas algumas sugestões para o trabalho com o ensino de gramática. 
1. Observe-se o trecho a seguir, em que já destaquei algumas passagens:

"A Gramática de usos do Português é uma obra que, diferentemente
do que se faz tradicionalmente entre nós, parte da observação dos
usos realmente ocorrentes no Brasil, para, refletindo sobre eles,
oferecer uma organização que sistematize esses usos. O que as lições
fazem, portanto, é organizar numa gramática da língua portuguesa
as possibilidades de construção que estão sendo aproveitadaspelos
usuários para a obtenção dos efeitos de sentido pretendidos." (NEVES,
2000 - Gramática de usos do Português, prospecto da Editora
UNESP).

O trecho acima já suscita a discussão de, pelo menos, sete aspectos. O primeiro diz respeito ao "que se faz tradicionalmente" quando o assunto é gramática. Com algumas exceções (por exemplo, PERINI, 1995), estamos acostumados, como argumenta MARCUSCHI (1998a, p. 2), a lidar com gramáticas ditas normativas e prescritivas, numa "imposição de usos" e numa "preocupação autoritária com normas estanques sem atenção alguma para com o que fazem os falantes" e considerando a língua "em si e por si mesma", "sem a participação do usuário". Em outras palavras, a falha de nossas gramáticas (e de nossos gramáticos!) é que as normas são estabelecidas com base em juízos de valor e preceitos que se fundamentam numa visão de língua como algo fixo e imutável, ignorando um continuum de variações que estão presentes nas línguas de modo geral.

É preciso deixar claro, no entanto, que a questão não é a existência da norma. Isso porque, como bem aponta MARCUSCHI (1998a, p. 6-7), "a normatividade se acha essencialmente ligada à natureza da língua" e "tem a ver de maneira essencial com determinação contextual", ou seja: "ela prescreve ou solicita uma determinada forma num determinado contexto, mas a determinação dessa forma e seu funcionamento estarão presos ao contexto". Explicando melhor: sabendo que a língua "é uma atividade humana, suscetível a constantes mudanças e sempre a serviço da comunicação entre os usuários", sua prática (normas de uso) não pode ser vista como 
neutra em termos culturais, nem descontextualizada. Entenda-se disso que a língua tem suas regularidades; e a regularidade na língua não é autônoma, isto é, não existe por si mesma, mas é "situada no contexto dos eventos comunicativos e de algum modo determinada pelas condições impostas pelas estruturas desses eventos." (MARCUSCHI, 1998a, p. 8). A título de exemplificação, pode-se dizer que o que se apresenta como regularidade numa conversação face-a-face não coincide necessariamente com a materialização lingüística de uma conversa por telefone, ou com a de uma aula, de um bilhete ou de um trabalho acadêmico. Marcuschi destaca, ainda, a posição de Cameron (1995, apud MARCUSCHI, 1998a, p. 8) de que "normatividade não tem a ver com autoritarismo ou purismo e sim com regularidade e adequação nas atividades comunicativas".

Importa, portanto, na organização de uma gramática (e no trato com a língua) buscar argumentos que estejam sempre baseados nas atividades comunicativas que os usuários da língua desenvolvem, para que assim possam, tais argumentos, servir de fundamentação às normas lingüísticas.

Considerações como essa remetem ao segundo aspecto apontado no trecho destacado anteriormente, referente à "observação dos usos realmente ocorrentes" numa língua. Como já foi comentado acima, os usos é que irão fundamentar as normas. Observar os usos significa observar a linguagem em funcionamento, como uma atividade dinâmica. Como conseqüência, o interesse não mais se atém ao sistema estritamente lingüístico, mas concentra-se na observação da linguagem em seu contexto de uso nos processos de interação. E onde se dão esses usos? Ou: quais são os contextos de uso? Numa visão bem ampla, podemos identificar, de imediato, os dois contextos básicos de uso: a oralidade e a escrita. Ou - para ficar mais fácil a referência - língua falada e língua escrita. Como são dois, portanto, os momentos de realização lingüística (com toda a sua variação), não se entende que se fale em gramática, e, principalmente, em ensino de gramática sem considerar também a língua falada. Isso porque a linguagem é uma atividade inerentemente interacional. E 
é essa concepção de linguagem como interação, como atividade, que deverá fundamentar a organização da gramática e, conseqüentemente, seu ensino. A natureza da linguagem relaciona-se às exigências que a ela fazem os usuários, às funções que ela desempenha. Assim, a forma particular que o sistema gramatical da língua assume está intimamente relacionada às necessidades pessoais e sociais de uso da linguagem. São as necessidades pragmáticas da interação verbal. E é a partir delas que, como argumenta NEVES (1996, p. 32), o usuário da língua irá "proceder a escolhas comunicativamente adequadas", "operar as variáveis dentro do condicionamento ditado pelo próprio processo de produção." Consideram-se, portanto, as pressões do uso, revelando, assim, o caráter dinâmico da língua. Dessa forma, dentro dessa concepção de linguagem, a língua é vista como "uma atividade no tempo real, cujas regularidades são sempre provisórias e sujeitas à negociação, renovação e mudança”. (Thompson, apud NEVES, 1994, p. 71)

Mais adiante essa questão da língua falada e da língua escrita será novamente abordada. Por ora, basta ter em mente que essas duas modalidades fazem uso da língua de forma diferenciada, tendo em vista suas diferentes condições contextuais de produção textual, o que o estudo/ensino de gramática tem de levar em consideração. E isso é o que a gramática normativa não faz!

O terceiro aspecto destacado no trecho remete a um ponto que considero crucial: a reflexão gramatical em lugar do ensino de uma terminologia, de uma nomenclatura. Uma tal visão de gramática significa sair da classificação das expressões lingüísticas, isto é, dos produtos e empreender a identificação dos processos constitutivos da língua (ou seja, constitutivos da conversação, do texto e da sentença), tema que está muito bem discutido em CASTILHO (1998).

Quero, na oportunidade, deixar registrada a minha convicção em favor do ensino de gramática na escola. Essa convicção não se traduz num ensino que se limite a difundir informação, elaborar listas e aplicar exercícios de treinamento. Postulo, ao contrário, que o ensino de gramática seja visto como uma atividade de reflexão - e 
de reflexão continuada -, de modo a levar o aluno a entender não os enunciados vistos isoladamente, mas os mecanismos e processos constitutivos da língua e que caracterizam esse sistema. Concordo com CASTILHO (1998) quanto à preferência pela expressão "reflexão gramatical", ao invés de "ensino de gramática". Na verdade, a adoção dessa terminologia reflete uma postura mais questionadora, e também mais científica, em relação ao estudo/ensino da língua. Como aponta POSSENTI (1996, p. 56), "refletir sobre a língua é uma das atividades usuais dos falantes e não há razão para reprimi-la na escola". E acrescenta: trata-se de "reorganizar a discussão, de alterar prioridades", colocando, dentre tais prioridades, a discussão de preconceitos lingüísticos (mais do que fazer análise sintática).

É preciso considerar, como aponta CASTILHO (1998, p. 22), que "a gramática não é o lugar das certezas absolutas". Assim, não "devemos transferir nossa capacidade de reflexão para o autor de uma gramática, por melhor que ele seja". Nesse caso, estaria sendo simplesmente passado para o aluno o "pacote gramatical", o que acabará afastando esse aluno da reflexão. (Além do mais, é bom lembrar que para isso ele não precisa de professor!). Estudar/ensinar/ fazer gramática deve, portanto, ser um debate contínuo. A partir de dados reais - começando pelos de língua oral, como será visto adiante - o debate tomará consistência em torno de hipóteses e questões sobre os dados, questões essas que poderão abrir caminhos para novas indagações e novas abordagens. Como bem argumenta GERALDI (1996, p. 136),

"mais do que encontrar uma resposta, o que vale na reflexão sobre a língua é o processo de tomá-la como objeto. As tentativas, os acertos e os erros ensinam muito mais sobre a língua do que o estudo do produto de uma reflexão feita por outros, sem que se atine com as razões que levaram à reflexão que se estuda."

Não se justificam, portanto, as "receitas", ou fórmulas prontas, ou "mágicas", tão esperadas (e, às vezes, solicitadas) por profissionais de magistério para se alcançar uma pretensa eficácia no ensino da gramática, ou de quaisquer de seus tópicos! Ao contrário, a eficácia 
poderá ser alcançada se se empreender a tarefa de "mostrar a língua" para o aluno, ou seja, de levá-lo a conhecer a estrutura da língua - o que significa conhecer o seu sistema, sua gramática - e, principalmente, conhecer a língua falada, que é a manifestação natural e espontânea da linguagem, com os processos e estratégias que ali se manifestam. O conhecimento dos processos de constituição da língua falada, dos mecanismos e estratégias de construção do texto falado - incluindose aí não só as estratégias textuais-discursivas mas os processos sintáticos e fonológicos envolvidos na produção dos enunciados e do texto - poderá evitar mal-entendidos de análise e descrição.

Dessa discussão/reflexão, desse debate fundamentado nos usos - tendo como ponto de partida o conhecimento que os alunos já possuem da língua quando chegam à escola, da língua usada no dia-a-dia, isto é, da conversação - decorrerá a sistematização desses usos, organizados de acordo com as suas possibilidades de construção. Essa sistematização e essa organização representam o quarto e o quinto aspectos destacados no texto do prospecto acima citado. Assim, a partir da organização dos fatos observados poderão ser formuladas regras gramaticais, essencialmente descritivas, que, por um lado, mostrem as regularidades encontradas, e, por outro, devem ser vistas como variáveis, em decorrência da própria variação do corpus examinado. Tal variação será, portanto, um reflexo dos usos diferenciados nos diversos contextos. Dessa forma, "a gramática deixará de ser vista pelos alunos como a disciplina do certo e do errado" (CASTILHO, 1998, p. 23), mas como um instrumento para se conhecer o real funcionamento da língua.

Nessa reflexão gramatical (que deverá nortear o ensino da gramática) é fundamental conceber a língua como um instrumento através do qual os homens interagem socialmente, sendo usado, como aponta NEVES (1997, p. 19, ao citar DIK, 1978 e 1989), com o "objetivo principal de estabelecer relações comunicativas entre os usuários". Ora, nos diferentes eventos comunicativos, ou seja, nas diferentes situações de uso da língua (as práticas sociais), seja a oral seja a escrita, os usuários vão estar fazendo escolhas dentre as possibilidades da 
língua para a construção de seus textos. Essas escolhas serão dependentes das condições de produção de um determinado tipo de texto. Tais possibilidades (que constituem o quinto aspecto aqui destacado) serão aproveitadas pelos usuários (sexto aspecto levantado) na medida da perspectiva que eles querem dar ao discurso a ser produzido. Por perspectiva discursiva entenda-se o objetivo do usuário, suas intenções, o que ele pretende com determinado texto, que sentido ele quer que seja construído, e assim por diante, o que é apontado no sétimo aspecto do trecho escolhido para a discussão desenvolvida nesta primeira parte da exposição.

Do que foi exposto até aqui, pode-se concluir que uma gramática fundamentada nos usos da língua é uma gramática que se diz funcional, na medida em que ela procura desvendar/descrever o funcionamento da língua. Dessa forma, pode-se lembrar DU BOIS (1993), quando diz que a gramática é sensível às pressões de uso das expressões lingüísticas na interação verbal, o que evidencia um "relacionamento íntimo entre as determinações do discurso e as da gramática." (NEVES, 1997, p. 27). Melhor dizendo, e concordando com HOPPER (1988), "é o discurso real que mantém a chave para a gramática". Conforme já discutido em DECAT (1999b, p. 213-214), segundo Hopper "o usuário da língua, ao construir seu discurso, não extrai as palavras, ou expressões lingüísticas, de um catálogo só porque elas se adaptam a uma construção sintática particular." Não se trata, pode-se dizer, de uma atividade que lembraria os "famosos" exercícios estruturais de preenchimento e substituição. Ao contrário, a forma assumida por uma palavra ou expressão é um reflexo de sua função num contexto de uso particular. Partindo-se, portanto, de uma concepção de linguagem como interação, apresenta-se, em decorrência, uma concepção de gramática que considere o efeito que os usos da linguagem, em contextos reais para propósitos comunicativos do falante, provocam na forma de sua manifestação lingüística. É dentro dessa visão que se pode entender a afirmação de Hopper, vista acima. E é também nesse enfoque funcionalista das relações entre discurso e gramática que se encaixam as postulações de DU BOIS 
(1993, p. 11), segundo o qual "a gramática é feita à imagem do discurso" (entendido, aí, como "uso"), mas esse (o discurso) "nunca é observado sem a roupagem da gramática”. Ou ainda, segundo HALLIDAY (1985), os usos é que dão forma ao sistema. "Em suma, e também segundo Hopper, uma gramática, dentro dessa visão funcionalista da linguagem, é sempre provisória e incompleta, e emerge do discurso." (DECAT, 1999b, p. 214). Pode-se dizer, então, que o uso de hoje é a regra de amanhã. E isso é o que deve estar presente nas discussões gramaticais, seja para a descrição da gramática, seja para seu ensino.

2. Para se falar em gramática de uma língua - seja seu estudo/ organização, seja seu ensino - não se pode deixar de lado a lingua falada, a manifestação lingüística levada a efeito na situação comunicativa mais espontânea, que é a conversação.

E quando se aborda a questão da língua falada logo se pensa em sua relação com a língua escrita, numa preocupação em estabelecer diferenças que conduzem a dicotomias não muito esclarecedoras. Em primeiro lugar, porque freqüentemente se observa o texto falado mas fazem-se observações sobre ele sob a ótica da escrita, isto é, usando-se um aparato terminológico próprio da escrita. Em segundo lugar, porque se colocam essas duas manifestações em pólos opostos, ignorando-se o continuum de variações que estão presentes nas línguas de modo geral e que se realizam tanto na fala quanto na escrita. Essa variação irá levar a um continuum de gêneros textuais, dentro do qual os textos se identificarão como mais próximos da fala ou mais próximos da escrita.

Não pretendo me alongar, aqui, em maiores considerações sobre as diferenças e semelhanças entre fala e escrita, visto que essa relação encontra-se discutida numa vasta bibliografia (nacional e estrangeira). Interessa, para o momento, ter em mente o fato de que se trata de duas modalidades de uso da lingua que decorrem de duas práticas sociais, cada uma com suas condições de produção específicas. São duas modalidades de uso de um mesmo sistema. Ora, 
se assim é, por que desconsiderar uma dessas modalidades nas atividades de reflexão gramatical? Por que trabalhar só com a escrita, ignorando que o conhecimento de uma língua (no sentido de sua aquisição) se dá pela modalidade oral? Se se concebe, como já foi apontado aqui, a linguagem como atividade, como interação, por que ignorar, em seu estudo/ensino, a forma mais natural (e primeira) de interação pela linguagem que é a língua falada?

Muitos foram (e, infelizmente, continuam sendo) os preconceitos em relação à língua oral/falada: "língua de analfabeto", "língua truncada", "fragmentada", "errada", "cheia de gaguejos", "o lugar do erro” (conforme postulam muitos gramáticos!), e por aí vai, numa discriminação de usos e de usuários! Posturas como essas revelam o desconhecimento de que a língua falada é um dos usos da língua demandados pela sociedade em que vivemos. E que cada uso estará atrelado a uma situação (ou contexto), o que permite que se perceba uma relação diferente entre fala e escrita e, conseqüentemente, um tipo de texto específico. Além disso, nessa relação fala/escrita, alguns usos serão mais intensos que outros, dependendo de serem decorrentes de contextos (ou situações) mais básicos de uso da língua, ou não. Assim, por exemplo, uma pessoa pode conversar mais por telefone do que face-a-face, por força das condições em que vive (por exemplo, se é uma pessoa que não pode sair de casa); é possível, também, que o uso da escrita por uma pessoa se restrinja a bilhetes - deixados, por exemplo, para o cônjuge ou para a empregada da casa - do que a situações que exijam maior formulação, como é o caso dos trabalhos acadêmicos. Isso quer dizer: as diferenças de uso vão levar a diferenças textuais. No entanto, mais do que considerar as diferenças entre fala e escrita é preciso considerar as diferenças entre situação de fala e situação de escrita, ou seja, entre as condições de produção textual nos diferentes contextos de uso, ou nas diferentes práticas sociais (a família, o diaa-dia, o telefonema, o escritório, a escola, o trabalho, etc., etc.). A isso se chama variação (que é decorrente dos usos, das práticas sociais). E tudo isso deve ser levado em conta numa gramática e no 
seu ensino. Em outras palavras: a língua falada deve constituir o ponto de partida do professor/estudioso para reflexões mais aprofundadas sobre a maneira como a língua funciona.

Infelizmente, muito se tem discutido sobre fala e escrita, mas pouco se conhece sobre o funcionamento e a estrutura da língua falada (ou melhor, da língua em seu uso em situação de oralidade). $\mathrm{E}$, nesse ponto, quero ressaltar que não vejo como um professor (de Português) possa ensinar uma língua que ele não conhece. É tão estranho quanto imaginar um médico que não conheça a estrutura e o funcionamento do organismo humano, ainda que em seus aspectos mais básicos (por exemplo, saber que sangue corre nas veias, que os rins funcionam como depuradores, filtros, etc., etc.). Como será que esse "médico" se conduz num diagnóstico de um cliente? Do mesmo modo, como um professor vai diagnosticar as dificuldades do aluno?

Conhecer a estrutura da língua significa conbecer o sistema da lingua, sua gramática. Conhecer a língua falada é conhecer os processos e estratégias que se manifestam na construção do texto falado, sejam eles de natureza textual-discursiva ou sintática e fonológica, como já foi apontado acima. Assim, equívocos de análise poderiam ser evitados. Por exemplo, muito do que se pensa ser interferência da oralidade na escrita nada mais é do que característica da língua de modo geral, ou seja, de seu sistema. Assim, poder-se-á verificar que um determinado fenômeno ou estratégia poderá ser mais freqüente na língua falada não porque seja próprio dessa modalidade, mas porque as condições de produção dessa modalidade propiciam o uso de determinada estratégia (mais do que na escrita, ou de maneira diferente de ocorrência). Exemplo disso é o caso da repetição. Considerada, muitas vezes, como um reflexo da incapacidade do usuário de construir um texto coeso e coerente, tem sido objeto de inúmeras e recentes análises que acabaram por mostrar tratar-se de um mecanismo que permeia todas as atividades de construção textual, seja na fala, seja na escrita, sendo própria da interação verbal. Ela é, portanto, um procedimento gramatical regular, uma estratégia na produção de textos. Assim, num estudo da "gramática da 
repetição", tem-se de levar em conta que se trata de um mecanismo da língua, do sistema, e seu uso dependerá das condições de produção de cada uma das modalidades. Importa, assim, levar ao conhecimento do aluno que, para uma determinada ocorrência na escrita, pode ser que não haja necessariamente uma correspondente na língua falada. Nesse caso, a situação de oralidade levará ao uso de outros mecanismos e estratégias (gramaticais, inclusive) mais apropriados à situação de oralidade. Os enunciados $a$ e $b$, abaixo, servem de ilustração, em que à repetição na língua escrita contrapõese o uso de intensificadores, na oral:

a) Carlinhos estragou a boneca da Aninha. Então ela chorou... chorou! (língua escrita)

b) Carlinhos estragou a boneca da Aninha e aí ela chorou até... (ou: de montão, etc.) - (língua oral)

Muito se tem falado também - e principalmente a partir dos Parâmetros Curriculares Nacionais, os PCNs - sobre a incorporação da língua falada no ensino da língua, e, no caso que interessa aqui, de sua gramática. Para essa incorporação, não basta colocar o aluno para falar (contar casos, ler em voz alta, declamar, representar, etc.); tem-se que conbecer profundamente como ela se estrutura. Só assim o professor poderá diagnosticar possíveis "interferências" na produção escrita. E nesse conhecimento da língua falada é preciso estar atento para as variações lingüísticas, quer regionais, quer sociais e, principalmente, individuais. E mais: necessário se faz atentar-se para o fato de que essas variações decorrem das práticas sociais, o que dará origem a diversos textos, a diversos gêneros textuais. $E$ é preciso, repito, mostrar essa lingua para o aluno, levando-o a se conscientizar de que, como bem demonstra POSSENTI (1996),

- não há línguas fáceis ou difíceis

- todos os que falam sabem falar

- não existem línguas uniformes

- não existem línguas imutáveis 
Dessa forma, amplia-se a noção de gramática da língua, de tal modo que seu estudo - e, conseqüentemente, seu ensino - possa inserir-se num contexto mais amplo, fundamentando-se numa reflexão contínua sobre os fatos reais da língua, evitando-se, assim, questões de ordem prescritivista e autoritária.

3. Nesta terceira parte da presente discussão serão feitas considerações sobre o trabalho com a língua falada e dessa para a escrita no que diz respeito ao estudo/ensino da gramática.

Como foi dito anteriormente, o ensino da gramática de uma língua pressupõe, obviamente, o conhecimento desse sistema que é a língua, ou seja, sua estrutura, sua organização. Também foi ressaltado que esse conhecimento se dá, primordialmente, através do estudo descritivo da língua em sua manifestação espontânea, que é a língua falada, através da atividade de interação mais natural que é a conversação.

Conhecer a língua falada não se restringe, no entanto, ao conhecimento da língua dita "familiar", mas abrange outras situações e contextos da prática social que caracteriza essa modalidade. E nesse trabalho de descrição/ensino da língua - e de sua gramática, em particular - é necessário considerar o que HYMES (1972) chama "competência comunicativa", ou seja, a habilidade que o usuário da língua tem de interagir socialmente por meio da linguagem. Segundo DIK (1989), essa competência do falante vai além da mera função lingüística de construção e reconhecimento de sentenças; ela envolve funções "mais elevadas" no uso que ele faz da língua. Assim, o ensino de gramática, numa abordagem funcionalista - fundamentada numa concepção de linguagem como "uma forma de atividade cooperativa estruturada", conforme aponta DIK (1989, p. 3) - terá de considerar não somente os aspectos estruturais, sistêmicos, mas também os aspectos relativos aos fins, aos propósitos do usuário ao construir e usar uma determinada expressão lingüística. No ensino da gramática, portanto, fazer somente a descrição da estrutura de uma sentença não será 
suficiente para se levar o aluno a entender, por exemplo, o significado de uma determinada expressão lingüística; será necessário que se faça referência, nessa descrição, ao falante, isto é, ao produtor daquele enunciado, ao ouvinte, ao contexto, aos papéis que desempenham na situação de interação determinada sócio-culturalmente. Isso significa incorporar a pragmática na gramática, não se admitindo, portanto, uma sintaxe autônoma. Tal incorporação decorre do reconhecimento de que os enunciados são multifuncionais, isto é, apresentam aspectos gramaticais, semânticos e pragmáticos. Assim é que, para DIK (1978, p. 6), uma gramática tem de ser "pragmaticamente adequada”, buscando explicações fora do sistema, verificando que fatores estão em jogo contribuindo para dar forma e significado à expressão lingüistica. Isso implica aceitar, por exemplo, que o significado emerge do discurso, bem como a estrutura gramatical. Relembrando DU BOIS (1993, p. 11), "a gramática é feita à imagem do discurso", entendido como "uso"; entretanto, é preciso considerar que, para se observar tal discurso, não se pode prescindir do aspecto gramatical.

Ora, o ensino da gramática deve, portanto, partir da observação do discurso, isto é, da manifestação lingüística em uso, começando pela língua falada. Para tanto, é necessário que o aluno "ouça" a língua oral, através de gravações. A essas se seguirão transcrições, para que, então, o aluno "veja" a língua oral, se conscientize da língua falada, com suas características e especificidades, para um posterior confronto com a língua escrita. O estudo/ensino de aspectos gramaticais deverá ser feito a partir desse material, procurando o professor não se descuidar dos aspectos textuais-discursivos, ressaltando, assim, a multifuncionalidade dos elementos da língua. Dessa forma, uma questão sintática como, por exemplo, a ordem da oração adverbial num enunciado pode ser melhor entendida se for discutido o valor pragmático-discursivo que a anteposição ou a posposição da oração adverbial terão como elemento de organização textual em situações reais de comunicação.

Também noções pragmático-discursivas como as de envolvimento e distanciamento poderão fornecer explicações mais satisfatórias 
sobre o uso dos pronomes pessoais, ou mesmo sobre o empregos dos tempos verbais. Vale lembrar, por exemplo, o distanciamento do falante em relação ao tópico do discurso, ou seja, ao assunto, que o uso do futuro do pretérito permite detectar. E as relações entre oral e escrita poderão ser melhor explicitadas em termos dessas e de muitas outras noções.

Pesquisas mais recentes, interessadas no estudo da gramática da língua - mais especificamente na sintaxe - têm procurado verificar a relação que existe entre essa última e a interação. Partindo da fala para a escrita, os estudos de sintaxe interacional examinam, inicialmente, a conversação, mostrando que o que tem sido chamado tradicionalmente de "sintaxe" está intimamente envolvido na organização interacional do discurso conversacional. São, assim, propostas várias maneiras de se pensar a sintaxe, que vão permitir integrar a produção das unidades sintáticas com a estrutura interacional. Tem-se, portanto, uma concepção dinâmica da sintaxe, sendo a gramática vista como surgindo do discurso, da própria interação, e por ela determinada. Segundo GIVÓN (1984), a estrutura sintática se "reajusta" por força da função pragmático-discursiva, por força das pressões do uso. Assim, por exemplo, a ordem das orações adverbiais no português, já comentada anteriormente, poderá estar servindo à função de "guia" para o ouvinte/leitor para o que vem a seguir no texto. Um outro fato que ilustra esse reajuste da sintaxe às necessidades discursivas manifesta-se numa conversação, quando se dá um trabalho conjunto dos interlocutores na construção de seu texto em termos sintáticos. Nesse caso, é comum um interlocutor continuar a fala do outro, expandindo-a, completando sintaticamente o enunciado por esse último iniciado.

O exame de como a sintaxe trabalha na interação real pode conduzir a um entendimento mais claro do que é a sintaxe. E é a partir do estudo da língua falada - especificamente da conversação, que é a mais mundana das formas de comunicação lingüística - que se poderá verificar o modo como os mecanismos da língua são explorados na produção real, e também verificar como as estruturas 
sintáticas são organizadas. Assim, a reflexão gramatical estará centrada nos processos que agem na construção de um texto. E a partir da observação desses processos é que poderão ser formuladas regras que irão constituir o reflexo das regularidades encontradas na língua. E será também dessa observação que se poderá verificar, e demonstrar para o aluno, que a língua é uma estrutura maleável e, por isso, suas regras irão variar de acordo com o corpus que está sendo examinado. Mas, é importante explicitar para o aluno, nessa reflexão, que as formas variáveis, não-fixas, da língua coexistem e, por isso mesmo, competem com as formas fixas, regulares, ou seja, aquelas determinadas pelo uso. Conduzida dessa forma, a reflexão gramatical será um passo inicial para uma posterior sensibilização do aluno para as regras ditas "prescritivas", que, como aponta CASTILHO (1998, p. 22), "correspondem ao chamado uso culto, mais prestigiado pela comunidade". Ainda segundo esse autor, dar prioridade, no ensino de gramática, à descrição sobre a prescrição significa permitir que a disciplina que se ocupa do ensino da gramática reassuma "sua verdadeira dimensão, que é a de esquadrinhar através dos materiais lingüísticos o funcionamento da mente humana." (CASTILHO, 1998, p. 23). E isso é o que pretende uma reflexão gramatical calcada nos processos que constituem a língua.

A preocupação com os processos de funcionamento da língua tem feito da conversação seu ponto crucial de análise. As reflexões gramaticais poderão encontrar na sintaxe intraturno, por exemplo, manifestações lingüísticas esclarecedoras sobre diferentes aspectos da organização sintática das frases (desvestidas, no caso, de seus elementos interacionais) bem como da organização interna das orações. Por outro lado, a observação de uma sintaxe interturnos permitirá que se desvende a participação conjunta dos interlocutores na construção de uma "sintaxe a dois", através das "falas colaborativas". Além disso, através de uma abordagem que incorpore à gramática considerações de ordem pragmático-discursiva, tal estudo permitirá que o aluno reflita sobre os usos de certos elementos da língua como, por exemplo, "mas", "agora", dentre muitos outros - que vão 
funcionar ora como marcadores discursivos, servindo à interação assinalando, muitas vezes, a tomada de turno - ora como conectores sintáticos, indicando as relações sintáticas de coordenação ou subordinação e promovendo (como acontece freqüentemente com "mas") a coesão do texto conversacional. Em outras palavras, uma reflexão gramatical assim orientada, e tendo como ponto de partida a língua falada, seja numa sintaxe intraturnos ou interturnos, poderá levar a um melhor entendimento do papel dos conectivos (principalmente os que têm mais de um valor semântico) nos processos de coordenação e subordinação; e também poderá conduzir à verificação de relações implícitas, ao lado das explícitas, entre orações e partes do texto, seja na língua falada seja na escrita, e que independem da presença de conectivos. Uma reflexão assim de base pragmáticodiscursiva, que considera fala e escrita, poderá esclarecer os usos do elemento "então", que, além de servir ao estabelecimento de relações sintáticas entre orações, funcionará, como operador discursivo, para dar ao enunciado de que faz parte uma orientação argumentativa.

Um aspecto da sintaxe que vem sendo muito examinado - e que venho pesquisando já há algum tempo, e ao qual já tive aqui oportunidade de fazer ligeiras alusões - é a maneira como se articulam (ou se "combinam") as orações no texto. Não se trata de uma análise classificatória de orações (coordenadas e seus tipos, subordinadas e seus tipos), como foi feito pela maioria dos estudos tradicionais. Trata-se de um estudo que procura identificar não só as relações semânticas mantidas entre as orações mas as funções discursivas que elas exercem no texto, por força da perspectiva que o usuário dá a seu discurso. Assim, funções como "guia" (citada acima), "ponte de transição", "fundo", "tópico", "retomada" do discurso antecedente (numa função anafórica) ou "projeção" para o discurso subseqüente (numa função catafórica) apresentam-se como novas categorias de análise para os mecanismos de coordenação e subordinação que, certamente, irão fornecer importantes subsídios para uma abordagem mais abrangente no ensino desses aspectos da gramática. 
Acostumado a trabalhar com sintaxe com base na língua escrita, o professor ou o pesquisador se defronta com uma importante questão quando se trata de lidar com a sintaxe na língua falada: qual a unidade a ser trabalhada na fala? Na escrita, já por tradição se faz uso das noções de sentença e oração. Como agir no caso da fala, já que nessa modalidade são produzidos, por força das condições de produção, textos com hesitações, interrupções, mudanças de direção do fluxo informacional?

Um caminho possível para trabalhar principalmente com as orações subordinadas e com o conceito de dependência consiste na adoção da noção de "unidade informacional", nome dado por CHAFE (1980) para caracterizar os "jatos de linguagem" que irão constituir o texto falado. Trata-se de "blocos de informação", que tendem a se caracterizar como constituindo uma única oração (mas não necessariamente). A utilização dessa noção de unidade informacional no ensino desse aspecto da gramática da língua vai permitir que se entenda muita coisa que está acontecendo na escrita e é equivocadamente tomada como interferência da língua falada. É o caso do fenômeno do "desgarramento" (isto é, ocorrência isolada como enunciado) da oração subordinada na língua escrita, o qual vem-se tornando muito freqüente, não só em jornais e revistas mas também em trabalhos acadêmicos. Esse fenômeno se encontra discutido mais detalhadamente em DECAT (1999a), e pode ser ilustrado pelos exemplos abaixo:

(c) "Na Câmara dos Deputados, a Comissão Externa sobre os Desaparecidos Políticos, presidida pelo deputado Nilmário Miranda (PT-MG) estuda a proposta do governo de indenizar os familiares dos mortos e desaparecidos políticos. Enquanto na Câmara Municipal de Belo Horizonte tramita o projeto para dar nomes de mortos e desaparecidos politicos mineiros a 42 ruas da capital." (Jornal de Casa, BH-MG, 9 a 15/5/93, apud DECAT, 1999a, p. 30)

(d) "E, enquanto as fardas agitam o Brasil, o FHC fica bebendo champanhe com os fardões, com a rapaziada da Academia Brasileira de Letras. Que comemorou 100 anos com boca livre" [...] (José Simão, Folha de S. Paulo, 22/7/97, apud DECAT 1999a, p. 32) 
Ou ainda, como em (e), em que se evidencia a ocorrência de uma oração adverbial final como um enunciado com "existência própria", expressão que costuma ser utilizada nas gramáticas tradicionais para definir sentença ou oração independente:

(e) "O erro foi de origem. O governo tinha que ter separado o joio - a aposentadoria no serviço público - do trigo - a dos demais cidadãos. Para ter como mostrar à sociedade que o grande problema está naqueles que consomem a maior parte dos recursos apesar de serem em número infinitamente menor." (Estado de Minas, Opinião, "Vitória dos privilégios", 19/6/98, p. 6)

Finalmente, gostaria de tecer alguns comentários sobre um processo muito importante para um melhor entendimento da relação entre língua falada e língua escrita e no qual o ensino de gramática poderá encontrar um caminho promissor. Trata-se da retextualização, que consiste nas operações realizadas na passagem de um texto falado para o escrito, e desse para aquele, envolvendo quatro possibilidades, conforme aponta MARCUSCHI (2000): a) da fala para a escrita (por exemplo, entrevista oral $\rightarrow$ entrevista impressa); b) da fala para a fala (conferência $\rightarrow$ tradução simultânea); c) da escrita para a fala (texto escrito $\rightarrow$ exposição oral); d) da escrita para a escrita (texto escrito $\rightarrow$ resumo escrito).

O objetivo de Marcuschi é construir um modelo que sirva para determinar o grau de consciência que têm os usuários da língua a respeito das diferenças entre fala e escrita, a partir da observação da própria atividade de transformação.

Assim, o ensino de gramática poderá encontrar, nesse exercício de transformação que o aluno é levado a executar, uma estratégia metodológica eficaz para conduzi-lo ao entendimento de que, mudando as condições de produção, as situações de uso, mudamse os textos produzidos, até mesmo em aspectos considerados pela gramática normativa como fixos, imutáveis, como se costuma postular a respeito dos aspectos gramaticais. É preciso que o aluno perceba que na transformação de um texto em outro estão envolvidas operações que podem levar a diferenças de estilo, a alterações no 
léxico, na organização das frases, nas relações sintáticas entre os elementos, e assim por diante.

Visto dessa maneira, o ensino de gramática estará vinculado ao discurso, considerando que os enunciados não ocorrem isoladamente. Partindo da fala para a escrita, é preciso levar o aluno a

\begin{abstract}
"conhecer os mecanismos e processos que regem essas modalidades dentro de um continuum, atentando para as condições de produção, para as pressões do uso sobre o sistema, enfim, tendo a convicção de que não há regras absolutas, mas regras para o uso social adequado da linguagem." (DECAT, 1999b, p. 218)
\end{abstract}

\title{
CONCLUSÃO
}

De tudo o que apresentei aqui, ficam algumas postulações. No estudo/ensino da língua (seja de sua gramática, seja de sua organização textual), deve-se:

a) partir da fala para a escrita, conhecendo-se os mecanismos e processos que regem essas duas modalidades, estabelecendo suas diferenças e semelhanças quanto ao uso preferencial de certas estruturas, já que o sistema é um só;

b) considerar o contexto de uso;

c) considerar os processos (as funções e as relações) mais que as formas (os produtos);

d) considerar a variação lingüística, a variação em função do uso, dos propósitos, dos gêneros textuais;

e) considerar as pressões do discurso, ou do uso, sobre o sistema, lembrando-se de que não há regras absolutas, mas regras para o uso social adequado da linguagem, ou seja, regras para o uso adequado da linguagem em suas diferentes práticas sociais;

f) considerar a gramática de usos, lembrando-se de que, muitas vezes, uma expressão lingüística não é uma verbalização plena da intenção do falante (em outras palavras: nem sempre o falante verbaliza plenamente sua intenção). Isso decorre, por exemplo, 
da informação que o falante tem acerca da informação que o destinatário tem no momento da fala. Por isso, a verbalização parcial será normalmente suficiente. Muitas vezes uma verbalização nãodireta pode ser mais eficaz, surtir mais efeito, do que uma expressão direta da intenção.

Finalmente, quando se trata de ensinar a língua (incluindo o ensino da gramática), é preciso levar em conta, como aponta MARCUSCHI (1998c), que:

a) todos os dialetos são igualmente bons para os fins comunicativos a que se destinam;

b) nem todos os dialetos podem ser dialeto padrão;

c) a heterogeneidade lingüística é a "contraparte lingüística da diversidade social";

d) as línguas variam e mudam porque são dinâmicas e porque não são determinadas de modo rígido.

Nesse sentido, a gramática será vista não como um conjunto de regras estabelecidas a priori - e sob a ótica da escrita - mas como uma renegociação na fala, emergindo do discurso, sendo, portanto, inerentemente interacional. Assim, no ensino de gramática, "o sistema deve ser estudado dentro do quadro de regras, princípios e estratégias que governam seu uso comunicativo natural" (NEVES, 1994, p. 68), ou seja, na situação de fala, de oralidade, e não a partir do exame exclusivamente da língua escrita.

Os sete aspectos levantados no texto referido no início desta exposição encontram ressonância na afirmação de POSSENTI (1996, p. 86) de que "ensinar gramática é ensinar a língua em toda sua variedade de usos, e ensinar regras é ensinar o domínio do uso". A propósito, tomando a poetisa Cora Coralina, no ensino da língua, de sua gramática, é preciso ter em mente que

\footnotetext{
“(...) a língua é viva e móvel. Os gramáticos a querem estática, solene, rígida. Só o povo a faz renovada e corrente sem por isso escrever mal." (CORALINA, 1984, p. 128)
} 


\section{REFERÊNCIAS BIBLIOGRÁFICAS}

CASTILHO, Ataliba Teixeira de. A lingua falada no ensino de português. São Paulo: Contexto, 1998.

CHAFE, Wallace L. The deployment of consciousness in the production of a narrative. In: CHAFE, Wallace L. (Ed.) The pear stories: cognitive, cultural, and linguistic aspects of narrative production. Norwood: Ablex, 1980.

CORALINA, Cora. Vintém de cobre - meias confissões de Aninha. 2. ed. Goiânia: Editora da Universidade Federal de Goiânia, 1984.

DECAT, Maria Beatriz Nascimento. Por uma abordagem da (in)dependência de cláusulas à luz da noção de "unidade informacional". Scripta, Belo Horizonte, PUCMINAS, v. 2, n. 4, p. 23-38, 1999a.

. Funcionalismo e gramática. Para sempre em mim: homenagem à Professora Ângela Vaz Leão. Belo Horizonte: CESPUC/PUCMINAS, p.213-220, 1999b.

DIK, Simon C. Functional grammar. Dorderecht: Foris, 1978.

. The theory of functional grammar. Dorderecht: Foris, 1989.

DU BOIS, J.W. Discourse and the ecology of grammar: strategy, grammaticalization, and the locus. Rice Symposium, MS, Santa Barbara: University of California, 1993.

GERALDI, João Wanderley. Linguagem e ensino: exercícios de militância e divulgação. Campinas: Mercado de Letras /ALB, 1996.

GIVÓN, Talmy. Syntax I. New York: Academic Press, 1984.

HALLIDAY, M.A.K. An introduction to functional grammar. London: E. Arnold, 1985.

HOPPER, Paul. Emergent grammar and the a priori grammar postulate. In: TANNEN, Deborah (Ed.). Language in context: connecting observation and understanding. Norwood: Ablex, 1988. p.117-134.

HYMES, Dell. On comunicative competence. In: PRIDE, J.B., HOLMES, J. (Ed.). Sociolinguistics. Harmondsworth: Penguin, 1972. p.269-293.

MARCUSCHI, Luiz Antônio. A gramática e o ensino de língua no contexto da investigação lingüistica. São Paulo, 1998a. Mimeografado.

. Caracterização das relações entre lingua falada e escrita. XII ENCONTRO NACIONAL DOS PROFESSORES DE PORTUGUÊS, Belo Horizonte, CEFET, 1998b. (Mimeo)

. A língua falada e o ensino de português. In: BASTOS, Neusa Barbosa (Org.). Lingua portuguesa: história, perspectivas, ensino. São Paulo: EDUC, 1998c. p.101-119. 
MARCUSCHI, Luiz Antônio. Da fala para a escrita: processos de retextualização. Recife, UFPE, janeiro de 2000. Mimeografado.

NEVES, Maria Helena de Moura. A gramática funcional. Boletim ABRALIN, Salvador, n. 15, p. 67-73, julho de 1994.

. A gramática de usos é uma gramática funcional. Boletim ABRALIN, Maceió, Imprensa Universitária/UFAL, n.19, p.27-38, 1996.

. A gramática funcional. São Paulo: Martins Fontes, 1997.

. Gramática de usos do português. São Paulo: Editora UNESP, 2000.

PERINI, Mário Alberto. Gramática descritiva do português. São Paulo: Ática, 1995.

POSSENTI, Sírio. Por que (não) ensinar gramática na escola. Campinas: Mercado de Letras / ALB, 1996. 